Running Head: Morality and Groups

\title{
Morality and Behavioural Regulation in Groups: A Social Identity Approach
}

\author{
Naomi Ellemers ${ }^{1}$, Stefano Pagliaro ${ }^{2}$, and Manuela Barreto ${ }^{3}$ \\ ${ }^{1}$ University of Leiden, the Netherlands \\ ${ }^{2}$ Seconda Università di Napoli, Italy \\ ${ }^{3}$ University of Exeter, United Kingdom and Lisbon University Institute (CIS, ISCTE-IUL)
}

KEYWORDS: Morality, Intragroup Regulation, Social Identity

Published in the European Review of Social Psychology, vol 24, pages 160-193.

Final version, 19 April 2013

The first and second author contributed equally to this paper - their names are listed in alphabetical order. This work was made possible due to a Spinoza grant from the Netherlands National Science Foundation (NWO) awarded to Naomi Ellemers and a FIRB 2012 grant from the Italian Ministry of Education and Research (MIUR; grant number RBFR128CR6) awarded to Stefano Pagliaro.

Please address all correspondence to Stefano Pagliaro, Seconda Università di Napoli, Dep. of Psychology, Via Vivaldi, 43 - 81100 - Caserta (ITALY), E-mail: stefano.pagliaro@ unina2.it 


\begin{abstract}
In recent years social psychologists have displayed a growing interest in examining morality - what people consider right and wrong. The majority of work in this area has addressed this either in terms of individual-level processes (relating to moral decision making or interpersonal impression formation) or as a way to explain intergroup relations (perceived fairness of status differences, responses to group-level moral transgressions). We complement this work by examining how moral standards and moral judgements play a role in the regulation of individual behaviour within groups and social systems. In doing this we take into account processes of social identification and self-categorization, as these help understand how adherence to moral standards may be functional as a way to improve grouplevel conceptions of self. We review a recent research program in which we have investigated the importance of morality for group-based identities and intra-group behavioural regulation. This reveals convergent evidence of the centrality of moral judgments for people's conceptions of the groups they belong to, and demonstrates the importance of group-specific moral norms in identifying behaviours that contribute to their identity as group members.
\end{abstract}




\section{INTRODUCTION AND OVERVIEW}

Morality refers to "principles concerning the distinction between right and wrong or good and bad behaviour" (Oxford American dictionary). On the one hand, this explains the importance of morality in guiding individual behaviour (Beauchamp, 2001), in particular in communities of people living together in groups (Gert, 1988). On the other hand, it has been noted that shared ideas about what is the "right" way to behave may vary, depending on the cultural, religious, or political context in which this is defined (Haidt \& Kesebir, 2010; Haidt \& Graham, 2007; Rai \& Fiske, 2011). When people agree about the "supremely important" goals and values that characterize their group or community (Giner-Sorolla, 2012), these may come to function as a moral standard that is used to define whether an individual can be considered a virtuous and "proper" group member (Tooby \& Cosmides, 2010). Even though such analyses suggest that intra-group dynamics and the desire to establish a distinct group identity are highly relevant to understand the implications of morality for the regulation of individual behaviour, this context has not been systematically taken into account in research on morality.

Extant work on moral psychology has mainly addressed individual-level moral decision making (e.g., Kohlberg, 1969; Piaget, 1965; Schwartz, 1970; see also, Turiel, 1983; 2006), or has identified the implications of group-level moral transgressions (e.g., ČehajićClancy, Effron, Halperin, Liberman, \& Ross, 2011; Miron, Branscombe, \& Biernat, 2010; Tarrant, Branscombe, Warner, \& Weston, 2012). In this review we examine how intra-group moral judgments impact upon people's social identities and behavioural coordination in groups (see also Ellemers \& Van den Bos, 2012). This is different from current approaches aiming to identify moral values that are universal across groups and cultures (such as fairness, or harm/care; Haidt, 2001). We complement existing insights by focusing on how moral behaviour in groups can be explained by self-categorization and social identification 
processes (Tajfel \& Turner, 1979; Turner, 1991). In doing this, we explicitly take into account the possibility that moral values that are shared by members of a particular group may be context-dependent and group-specific. Thus, instead of considering how generic moral guidelines and moral judgments (e.g., fairness, empathy, altruism) may help suppress selfish and/or aggressive behaviour (e.g., Tomasello \& Vaish, 2013), we introduce a grouplevel analysis to address the group-dynamic function of shared moral values. In this contribution we review a program of research that examines how adherence to the moral standards of the group can help achieve or maintain a positive group-level conception of self (see also Ellemers \& Van den Bos, 2012; Leach, Bilali, \& Pagliaro, forthcoming; Pagliaro, 2012).

We propose that our analysis may help understand why people adhere to shared moral norms, even when these prescribe behaviours members of other groups may consider immoral (see also Giner-Sorolla, 2012). We demonstrate that group-specific moral norms impact upon behavioural choices of individual group members, regardless of the content (e.g., the individualistic vs. collectivistic nature) of the behaviour prescribed. We also show that moral guidelines provided by members of another group fail to have similar effects, because people consider moral judgments of outgroup members less relevant to their social identity.

This contribution is structured as follows: first, we explain our group-level approach to morality, in which we consider the different functions shared moral values may have for the way people define and maintain a positive and distinct social identity. We note how this differs from work that examines the impact of specific moral concerns on individual moral decision making, and explain how our reasoning builds on and extends research that illustrates the social implications of moral trait evaluations in individual impression formation. We then review a recent program of research that specifically addresses the role of social identity and self-categorization processes and the way these are relevant to moral 
concerns within groups, by examining the social functions of shared moral values and moral evaluations in regulating the behaviour of individuals in group contexts.

\section{THE SOCIAL FUNCTIONS OF MORALITY}

Morality refers to standards of human virtue (Brandt \& Reyna, 2011), that direct people's actions (Beauchamp, 2001). Moral standards help coordinate social interactions in communities of people living together, for instance by suppressing selfish or aggressive behaviour (De Waal, 1996; Rai \& Fiske, 2011). However, what people consider morally "good" (see also Giner-Sorolla, 2012) may differ between groups and cultures (Sachdeva, Singh, \& Medin, 2011). Indeed, group-specific moral standards can be used to judge whether the individual is a "proper" and good group member (Gert, 1988; Lind \& Tyler, 1988), with social exclusion being the ultimate consequence for those who do not behave in line with group morals (Tooby \& Cosmides, 2010). In a recent analysis, Ellemers and Van den Bos (2012) elaborated on this possibility, and noted that identifying what is "right" or "wrong" can serve various social regulatory functions, which play a role at different levels of analysis. In addition to seeing moral goals and values as providing a guideline for the resolution of intra-personal moral dilemmas, Ellemers and Van den Bos (2012) thus explore the role of moral judgments in interpersonal, group-level and intergroup processes, to argue that shared moral standards can be part of people's social identities. This helps individuals define who they are and where they belong, by providing them with self-relevant behavioural guidelines they can use to express a distinct and specific group-based identity.

In line with this analysis, we approach morality from a social identity and selfcategorization perspective (Tajfel, 1978; Tajfel \& Turner, 1997; Turner, 1987; see also Ellemers \& Haslam, 2011). This allows us to consider moral guidelines and moral transgressions in relation to group-level conceptions of self, group-based behavioral guidelines, and intra-group respect. A social identity perspective helps us to understand the 
role of morality in the value people attach to the groups they belong to, and the importance of moral judgments in establishing a distinct group identity (Ellemers \& Van den Bos, 2012). This also elucidates that individual behavioural choices are made in the context of moral goals shared by self-relevant social groups. Evolutionary accounts of morality consider the necessity for cooperation in groups as the primary origin for the development of moral guidelines (see Tomasello \& Vaish, 2013, for an overview). Such accounts see empathy, altruism, and cooperation in social communities as key indicators of moral behaviour that explain why appeals to moral values benefit society. However, such analyses of universal moral values cannot explain moral value conflicts between different groups in society, nor do they help understand why what some consider "immoral" behaviour (e.g., euthanasia, abortion, the use of firearms) can be seen as "moral" by members of other political, religious, or ethnic groups (Giner-Sorolla, 2012; Haidt \& Graham, 2007).

The notion that shared moral values may function to define a distinct social identity thus fundamentally differs from approaches that consider morality as a generic guideline that helps suppress selfish or aggressive behaviour (Haidt, 2008). When members of a particular social group agree upon specific moral standards, this provides them with a definition of what is considered right and wrong within their group-which is not necessarily shared with other groups. To the extent that individual group members behave in line with these moral guidelines, they can anticipate being respected as "good" group members. The social identity approach explicitly takes into account the possibility that people try to differentiate their group from relevant other groups. As a result, different behaviours, values, or goals may be seen to characterize one's group, depending on whether and how these may contribute to the group's distinct identity. Indeed, in principle, even negatively valenced group characteristics may fulfill the aim of establishing a distinct group identity (Mlicki \& Ellemers, 1996). This perspective allows us to understand that shared goals or values that characterize the group 
may come to be seen as the only "right" way for group members to behave, thus elevating them to the level of group morals.

Thus, against the background of generic moral concerns (e.g., harm/care) that may shape personal values, beliefs and preferences, the awareness of specific moral values and guidelines that are characteristic for one's group also tend to impact on what people consider the "right" way to behave. The importance of other people's (anticipated) judgments in moral behaviour has been considered before (see for instance research on consumer intentions to protest against retail organizations; e.g., Cronin, Reysen, \& Branscombe, 2012). For example, it has been argued that what is generally considered as a personal belief about the moral nature of a specific behaviour can be based on what others around us regard as moral (e.g., Manstead, 2000). Likewise, Batson (2008; see also Batson, Kobrynowicz, Dinnerstein, Kampf, \& Wilson, 1997; Batson, Thompson, \& Chen, 2002; Batson, Thompson, Seuferling, Whitney, \& Strongman, 1999) has noted that the behavioural choices people make in moral dilemmas do not necessarily reflect their own preferences, but are also determined by the concern of appearing moral in the eyes of others. Batson and colleagues refer to this phenomenon as indicating "moral hypocrisy", and contrast this with the tendency to behave in line with one's own moral principles which they designated as "moral integrity" (Batson, 2008).

Our current analysis builds on these insights, but it differs from these prior approaches in two ways. First, we consider both personal beliefs and social norms as relevant concerns in determining moral behaviour. That is, we explicitly address how group-specific moral norms impact upon personal preferences held by individual group members to determine their behavioural choices. Second, we specify the nature of the 'others' whose moral judgment is anticipated. That is, we argue for the role of those who share the same group identity (rather than outgroup members) as defining what is moral, and thus also as relevant judges of the morality of one's actions. Thus, we focus on group-specific moral norms as these prescribe 
how "a good group member" should behave. In the next section we will elaborate on the importance of intra-group evaluations of moral behaviour, by considering empirical evidence that illustrates the impact of moral concerns and moral evaluations in social judgments.

\subsection{The importance of morality in social judgments}

There is a long-standing tradition in psychology to address individual differences in the tendency to cooperate, show empathy, behave fairly, and to adhere to or deviate from social norms (see also Haidt, 2001; Turiel, 1983), even if these are not always explicitly referred to as indicating differences in "morality" (Haidt \& Kesebir, 2010). The way people tend to behave towards others is considered a very basic dimension of social judgment that is highly relevant to impression formation of individuals as well as of groups (e.g., De Bruin \& Van Lange, 1999; 2000; Cuddy, Fiske, \& Glick, 2008; Leach, Ellemers, \& Barreto, 2007; Martijn, Spears, van der Pligt, \& Jakobs,1992; Phalet \& Poppe, 1997; Vonk, 1996; Wojciszke, 2005). Some of this work organizes the traits that people tend to ascribe to themselves and others into two broad clusters, usually referred to as warmth and competence (e.g., Cuddy et al., 2008). More recent empirical evidence suggests that the broad cluster of interpersonal behaviours subsumed under the label "warmth" actually encompasses two separate and more specific dimensions, distinguishing between morality and sociability (Leach et al., 2007; see below for more details). While sociability refers to a target's ability or intention to form social connections with others (e.g., friendliness), morality speaks to the perceived correctness or (contextual) appropriateness of social behaviour (e.g., trustworthiness), that is relevant to our current analysis.

Several studies suggest that people respond more immediately and spontaneously to social information indicating morality rather than competence or sociability. For instance, less time is required to detect trustworthiness in a face than to detect competence or sociability (Willis \& Todorov, 2006). Furthermore, evidence from a memory confusion paradigm revealed that same sex individuals were spontaneously categorized on the basis of 
positive or negative information about their moral behaviour, rather than their competence (Van Leeuwen, Park, \& Penton-Voak, 2012). Self-reports also indicate that in social interactions people primarily express an interest in understanding whether someone's intentions are beneficial or harmful, rather than whether or not they are competent in enacting those intentions (e.g., Cuddy et al., 2008).

The great importance people attach to morality in social interactions also emerges from work examining whether and how information about specific behaviours impacts upon broader trait inferences. That is, so-called negativity effects-in which observers place greater weight on negative than positive information when forming an impression of othersare particularly pronounced for behaviours relevant to morality. As a result, a single instance of dishonest behaviour can spoil previous expectations of honesty. By contrast, a single instance of honest behaviour is not sufficient to overcome or repair an expectation of dishonesty (Reeder \& Coovert, 1986; Reeder \& Brewer, 1979). More generally, behaviours indicating (the absence of) morality are thought to be asymmetrically related to trait inferences, with negatively valenced behaviours having a larger impact than positive moral behaviours (Reeder, Pryor, \& Wojciszke, 1992; Trafimow \& Trafimow, 1999). In line with this reasoning, Skowronski and Carlston (1987) demonstrated that dishonest behaviours are more predictive of perceived immorality than honest behaviours are seen as diagnostic of morality. This is the case because people anticipate that moral individuals would never be dishonest, while immoral individuals may sometimes display honest behaviour (see also Rothbart \& Park, 1986).

Thus, a substantial amount of research (e.g., De Bruin \& Van Lange, 1999; 2000; Martijn et al., 1992; Vonk, 1996; Wojciszke, 2005; Wojciszke, Bazinska, \& Jaworski, 1998) attests to the importance people attach to information conveying the moral implications of people's behaviours, rather than their competence. Morality dominates impression formation, 
even in situations where competence would appear to be highly relevant, such as when the ultimate goal is to achieve optimal task performance.

It is important to note that in some of this research this was examined by contrasting competence information with information implying people's broader social intentions, encompassing traits indicating morality (e.g., honesty, sincerity) as well as sociability (e.g., helpful, good-natured). Nevertheless, a series of studies by Leach et al. (2007) demonstrated that judgments of morality and sociability emerge as theoretically and empirically distinct dimensions in positive evaluations of the ingroup. Taking into account this more precise distinction between morality, sociability, and competence proposed by Leach et al. (2007), Brambilla and colleagues examined the way people form impressions about other individuals (Brambilla, Rusconi, Sacchi, \& Cherubini, 2011) and groups (Brambilla, Sacchi, Rusconi, Cherubini, \& Yzerbyt, 2012) based on trait information indicating morality vs. sociability or competence. In this research morality and sociability consistently emerged as conceptually distinct dimensions in the evaluation of social behaviours (see also Anderson \& Sedikides, 1991; Trafimow \& Trafimow, 1999). Additionally, this research revealed that individuals are more interested in gathering information about morality (than sociability and competence) when asked to form an impression about other individuals or groups (Brambilla et al., 2011; 2012).

To examine the further implications of such impression formation, a recent study examined people's behavioural intentions towards a newcomer at work, depending on the information they had received about the morality and competence of this individual (Pagliaro, Brambilla, Sacchi, D’Angelo, \& Ellemers, in press). Seventy-nine employees of primary schools (teachers and administrative staff) received a table, allegedly reporting a description of the characteristics of a prospective school manager. Specifically, following the procedure developed by Brambilla and colleagues (2011; 2012), employees received a short page in which the prospective school manager was described in terms of six characteristics, three 
referring to morality and three indicating competence. The trait information participants received in this way characterized the new manager as being high vs. low in morality (e.g., honesty, sincerity) and high vs. low in competence (e.g., intelligence, skilfulness). The school employees in this study reported a more positive emotional response towards the prospective new manager who was described as a moral (vs. immoral) person (see Table 1). As a result, employees also indicated a greater willingness to engage in discretionary behaviours favouring the new school manager (e.g., spend time to show him/her the city) when they thought this individual was moral rather than immoral. By contrast, information indicating the (lack of) competence of the prospective new school manager impacted less strongly upon the emotional responses reported by school employees. More importantly, their intentions to behave in ways that might benefit the new manager were not affected by information indicating competence or lack thereof.

Similar results were obtained by Barreto, Haslam, and Kerridge (2012) who examined the impressions participants formed of an ingroup leader. Participants read about an ingroup leader who had reported on the ingroup's finances in ways that were described as competent, incompetent, honest (moral), or dishonest (immoral), in a 2(dimension) X 2(valence) design. Importantly, the exact same behaviour (e.g., resulting in mistakes in the financial report) was described as either due to incompetence or to immorality, controlling for the content of the actual behaviour (within negatively and within positively valenced conditions) and its most immediate consequences for the group. Group members were more positive about and more willing to endorse an ingroup leader who was described as moral or as competent, than a leader who was described as immoral or as incompetent, showing an unsurprising effect of valence. Importantly, however, leadership endorsement was significantly more affected by information about the leader's morality than by information about the leader's competence. As a result, participants were significantly less likely to be positive about and to endorse the immoral leader than the incompetent leader. 
In sum, different strands of research convey the profound implications of traits and behaviours that indicate morality in social impression formation. We propose that the predominance of moral evaluations in the impressions people form of other individuals and groups also resonates in the way people think of themselves and the impression they evoke among others that are important to them. In the next section we therefore examine the implications of moral evaluations for people's motivation to be (considered) moral by others - and other ingroup members in particular.

\subsection{The motivation to be (considered) moral}

Morality not only dominates the impressions people form of others around them, it also is a primary determinant of self-views. For instance, morality emerged as the most important guiding principle for individual behaviour across cultures (Schwartz, 1992). Likewise, Rodriguez Mosquera, Manstead, and Fischer (2002), examining samples in different cultural groups, consistently found that individuals who were asked to report how they would feel if they were thought to be dishonest or untrustworthy (vs. honest or trustworthy) were more likely to report negative feelings about themselves (see also the holier than thou effect; Epley \& Dunning, 2000). A similar conclusion may be drawn from Monin and Jordan's (2009) work on moral self-regard - that part of the self-concept that indicates the extent to which people think of themselves as a moral person in a particular situation.

Because of the importance people attach to moral goals and moral self-views, and the severe and far-reaching implications of being seen to act immorally, people are highly concerned when their moral values are called into question by others who are important to them, and are extremely motivated to behave in ways that help them appear as being moral in the eyes of these others. This was demonstrated, for instance, in a series of studies in which research participants were asked to reach a joint decision with a team mate who indicated disagreement with their moral values (vs. someone who held opposing material interests). 
Results of these studies revealed that within-team disagreement about moral values (rather than interests) was more likely to impact upon people's sense of self and identity (Kouzakova, Ellemers, Harinck, \& Scheepers, 2012). Accordingly, cardiovascular indicators showed that moral value disagreements within the team induced a negative physiological state suggestive of threat - indicating the perceived inability to cope with the situation. By contrast, within-team disagreement about material interests raised a positive state of challenge - a cardio-vascular response pattern indicating that the body mobilizes energy to address the situation (Kouzakova, Harinck, Ellemers, \& Scheepers, under review).

Additional evidence that people are motivated to behave in ways that their group considers moral was obtained in a series of studies that examined implications of having an ingroup representative frame the achievement of equal employment opportunities for ethnic minorities in the Netherlands as a moral ideal (instead of an obligation). Results revealed that white student participants or white employees who were asked by an ingroup representative to consider the achievement of equal opportunities as a moral ideal were more successful in generating ideas about what they might do to achieve this ideal, and were more inclined to endorse affirmative action measures (Does, Derks, \& Ellemers, 2011). Additionally, contemplating ways in which they might contribute to achieving the moral ideal of equal employment opportunities raised a cardiovascular response pattern indicative of a positive state of challenge, rather than a negative state of threat (Does, Derks, Ellemers, \& Scheepers, 2012).

The motivation to be considered a moral group member was also examined in a series of studies in which an Implicit Association Test (associating pictures of women with or without a headscarf with positive and negative pictures) was presented to female white participants either as a test of moral values or as a test of the ability to combine different stimuli with specific key presses. Results of a first set of studies revealed that participants were more concerned about the social implications of their test performance when they 
thought the test assessed their morality rather than their competence. Accordingly, research participants were more inclined to suppress their implicit behavioural bias against Muslim women on the IAT when they thought the test was diagnostic of their morality rather than their competence (see Table 2). In a follow-up study using the same experimental design, indicators of brain activity assessed with event-related electro-encephalogram measures (ERP's) revealed that participants who thought of the task as a test of their morality (rather than their competence) showed evidence of increased attention for the task stimuli and greater concern about giving a correct response (Van Nunspeet, Ellemers, Derks, \& Nieuwenhuis, in press).

Based on this initial work, a further series of studies was conducted, to examine whether the tendency to suppress bias as a way to appear moral would be more pronounced when being evaluated by an ingroup audience, rather than an outgroup audience. This time, at the outset of the study participants were allegedly placed into minimal groups, based on their style of decision making (Van Nunspeet, Derks, Ellemers, \& Nieuwenhuis, 2013). While working on the IAT (associating pictures of women with or without a headscarf with positive and negative pictures), participants received feedback from a female white confederate. This individual was introduced either as a minimal ingroup member or as a minimal outgroup member, by specifying their preferred style of decision making. After each trial of the IAT, participants were presented with a video still in which the confederate non-verbally indicated approval - smile and 'thumbs up' for correct responses - or disapproval - frown and 'thumbs down' for incorrect responses. Two studies using this methodology revealed converging results. The greater tendency to suppress implicit behavioural bias against Muslim women and to show increased attention and response monitoring in ERP's when the IAT was presented as a test of morality (rather than competence; as in Van Nunspeet et al., in press) most clearly emerged when participants thought their behaviour was monitored by a minimal 
ingroup member, rather than an outgroup member (Van Nunspeet, Derks, Ellemers, \& Nieuwenhuis, 2013).

In sum, results from a range of psychophysiological, self-report, and behavioural measures obtained in different research paradigms, all suggest that people try to behave in ways that make them seem moral, and suffer distress when their morality is called into question, especially by ingroup members (for overviews, see: Ellemers, \& Van Nunspeet, in press; Ellemers, Van Nunspeet, \& Scheepers, in press). In the next section, we will elaborate on the implications of the motivation to be (considered) moral for people's group-based identities, as we examine the morality of one's group as a potential source of positive identity.

\subsection{Morality as a source of positive identity}

The social identity approach (Tajfel \& Turner, 1979) proposes that - in principle - any evaluative dimension can form the basis for a positive evaluation of the ingroup. Thus, much of the empirical work in this area has not systematically considered the nature of the dimension on which groups are compared as being theoretically meaningful. As a result, the majority of research on positive ingroup evaluations has in fact examined effects of the relative competence of the group - indicated for instance by the group's performance on an experimental task, or the societal status of different natural groups. Only recently have researchers begun to explicitly address the relative importance of morality (vs. competence and sociability) as a source of positive ingroup identity, in order to examine the role of morality for the group-level self-concept (Leach et al., 2007).

A series of studies clearly established that evaluations of the group's morality are statistically distinct from evaluations of the group's competence as well as its sociability (Leach et al., 2007). That is, in four different data sets (Leach et al., 2007; Studies 1, 2a, 2b, and 3) exploratory as well as confirmatory factor analyses revealed that different characteristics that were used to evaluate the group were best represented in a three factor 
solution. Although these factors were allowed to covary, they consistently showed only weak intercorrelations or cross-loadings (below .30). For further analyses, partial correlations were used to establish the unique relation between each of these evaluative components and other variables of interest.

In a first study, Dutch student participants were asked to indicate the extent to which they deemed important that the various groups to which they belong possess traits referring to morality, competence, and sociability. Participants indicated that they considered traits referring to morality (honest, sincere, trustworthy) as more important indicators of the value of a group they belonged to than traits indicating the group's competence (competent, intelligent, skilled) or sociability (likable, warm, friendly). In a second study participants were assigned to experimental groups of global vs. detailed perceivers, allegedly on the basis of their performance on a bogus task that assessed their perception style. Then, identification with the ingroup was measured, participants were asked to rate the ingroup on characteristics relating to morality, sociability, and competence, and to provide an overall evaluation of their group. The results of this study revealed that the level of identification with the experimentally created ingroup was uniquely related to participants' ascription of ingroup morality. That is, the more they thought their group was moral, the more participants were inclined to report that they identified with this group. The ascription of competence or sociability to the ingroup was not related to the level of ingroup identification participants reported (Leach et al., 2007; Study 2).

These initial studies were followed up with a set of studies examining students from Leiden University as a natural group. The ingroup (Leiden University students) was compared with an outgroup consisting of students from the University of Amsterdam (Leach et al., 2007, Study 3); experimental instructions framed the ingroup as relatively successful or unsuccessful, compared to the outgroup, on various domains allegedly valued by prospective employers. Regardless of whether the ingroup was presented as relatively successful or 
unsuccessful, the morality of the ingroup emerged as the most important determinant of a positive evaluation of the ingroup.

In a final set of studies (Leach et al., 2007; Studies 4 and 5) bogus information was provided to induce high vs. low ingroup morality (e.g., the alleged tendency of Leiden University students to cheat on exams), and this was crossed with information indicating high vs. low competence (the alleged quality of Master theses of students from Leiden University; Study 4) or sociability (the alleged tendency of students from Leiden University to behave in a friendly manner; Study 5). In both studies, pride in the ingroup only depended on the perceived morality of the group (see Table 3). That is, participants who thought students from their university were more moral than students from other universities reported more pride in their group membership than participants who were led to believe students at their university were relatively less moral. Importantly, when information about different dimensions of group virtue was available, the perceived morality of the ingroup impacted upon the level of ingroup pride reported, regardless of the information participants had received about the perceived competence (Study 4) or sociability (Study 5) of the ingroup. Likewise, only when the morality of the ingroup seemed deficient did participants distance themselves from the group, by emphasizing intra-group differences (Study 4) or claiming they were different from other group members (Study 5; see Table 3). Again, when explicit information about the group's morality was available, informing participants that their group was lacking in competence or sociability did not contribute to the tendency to distance the self from the ingroup.

Further evidence for the link between perceptions of morality and group identity can be gathered from research by Barreto et al. (2012), noted above, where participants were asked to indicate their impressions of an ingroup leader described as competent, incompetent, moral, or immoral (in a 2 (dimension) X 2 (valence) design). In a series of studies, participants indicated that the leader described as immoral and the leader described as 
incompetent were equally damaging to the ingroup, but they rated the immoral leader as significantly less prototypical of the group than the incompetent leader. A separate study replicated this effect and additionally showed that when no information about leader morality was provided, leaders who were described as prototypical of the group were seen as more moral than leaders who were described as atypical of the group.

Together, these studies demonstrate that morality is a primary source of ingroup virtue, and suggest that positive evaluations of a group in terms of morality can contribute more to a positive social identity than other dimensions of ingroup value - relating for instance to the group's competence or sociability. Following the analysis proposed by Ellemers and Van den Bos (2012), and in view of the current goal to understand the relation between morality and behavioural regulation in groups, this raises the question of how the morality of the ingroup impacts upon emotional responses and behavioural intentions of individual group members

This question was addressed in a series of studies by Brambilla, Sacchi, Pagliaro, and Ellemers (in press). After pretesting stimulus materials for comparability and credibility (to rule out alternative explanations for effects) Italian student participants were asked to evaluate a target individual who was presented as an ingroup member (someone of Italian descent) or outgroup member (someone of Indian descent). To introduce this target individual, some additional information was provided in the form of a score-card, allegedly indicating whether the individual had scored high or low on a series of traits. In the first study ( $\mathrm{N}=83$ ), participants only received information relating to the morality of the target individual (e.g., honesty, sincerity). In follow-up studies, additional information was provided to convey high vs. low competence (e.g., competence, skilfulness; Study 2; N = 165) or sociability (e.g., warmth, friendliness; Study 3; $\mathrm{N}=108$ ), in addition to information indicating the morality of the target individual. Subsequently, participants were asked to indicate whether and how (i.e., in terms of the group's identity or the group's safety) they felt 
threatened by the target individual. Finally, participants were invited to indicate their behavioural intentions to approach (e.g., cooperate with) or avoid (e.g., distance themselves from) the target individual.

The results of all three studies showed converging results. The morality of the target individual significantly affected participants' experiences of threat as well as their behavioural intentions (in Studies 1, 2 and 3), and no comparable effects were observed as a result of differences in the competence (Study 2) or sociability (Study 3) of the target. However, the impact of the target's morality differed depending on whether the target represented an ingroup or an outgroup member. An ingroup target lacking in morality was experienced primarily as a threat to the image of one's group, whereas an immoral outgroup target was seen to represent a threat to the safety of one's group. Even though both ingroup and outgroup targets raised behavioural avoidance rather than approach intentions when lacking in morality, the desire to avoid the target was mediated by the experience of group image threat in the case of an ingroup target, and by group safety threat in the case of an outgroup target.

Prior work on the black sheep effect has also demonstrated that people tend to distance themselves from and exclude ingroup members who fail to meet the group's norms or standards (e.g., Marques, Yzerbyt, \& Leyens, 1988). However, the studies reviewed above are the first to establish the specific importance of moral shortcomings (rather than a lack of competence or sociability) in this context. Additionally, the studies reviewed here demonstrate the process underlying group-members' responses to the moral inadequacy of an ingroup target and clarify how this differs from their responses to an outgroup target. Specifically, intentions to avoid morally deficient ingroup targets are motivated by the farreaching implications of such shortcomings for the image of the group - not because of group safety concerns. Even though people are equally likely to avoid an outgroup target that is lacking in morality, they do so for different reasons, as group safety concerns predominate 
and are cause for behavioural avoidance when confronted with an immoral outgroup member.

\section{MORALITY AND BEHAVIOURAL REGULATION IN GROUPS}

So far we have identified the social functions of morality, and have presented empirical evidence to demonstrate how moral evaluations relate to people's individual and group-based identities. In the remainder of this contribution we will consider the further implications of these processes for behavioural regulation within groups. We have noted above that the social identity approach (Tajfel \& Turner, 1979) clarifies how membership in social groups can help individuals define who they are, where they belong, and how they should behave. As a consequence, social groups are likely to affect individual behaviour, not only because of interdependence and instrumentality concerns, but primarily for more abstract meaning-seeking and social-distinctiveness reasons (Turner, 1991).

Group norms - indicating what the group considers the right and "proper" thing to do - constitute an important guideline for the behaviour of individual group members (Turner, 1991). Consequently, adherence to group norms should help earn respect from other ingroup members, as it demonstrates one is a "good" group member, who is willing to let go of individual behavioural preferences in order to behave in ways that are approved by the group (see for instance, Barreto \& Ellemers, 2000). Conversely, the transgression of moral norms can have severe social implications. In fact, moral norm transgression should be seen as more socially consequential than the transgression of competence-based norms (see also Skowronski \& Carlston, 1987). In the next sections we will review research examining when and why this is the case, and explore whether the tendency to adhere to morality-based group norms actually can be explained from social identity concerns.

\subsection{Organizational ethics and employee cooperation}

As a first illustration of the implications of moral norm adherence for behavioural regulation in groups, we examine organizational morality as a relevant concern in the 
coordination of individual effort in organizational contexts. Prior efforts to examine how social identity concerns impact upon behaviour in organizations have revealed that the willingness of individual employees to cooperate with each other and to exert themselves towards the achievement of organizational goals depends on the extent to which they feel committed to their work team or organization (Ellemers, De Gilder, \& Van den Heuvel, 1998; Ellemers, De Gilder, \& Haslam, 2004; Haslam \& Ellemers, 2005; 2011). Prior work has also shown that employees who take pride in the organization report greater work satisfaction and organizational commitment. In fact, these relations were even observed among volunteer workers who are not bound to the organization by instrumental concerns or contractual obligations (Boezeman \& Ellemers, 2007). The experimental research reviewed above suggests that perceiving the organization as moral may constitute an important source of organizational pride. As a result, organizational activities or practices that attest to the morality of the organization should elicit positive work attitudes that foster cooperative behaviour and rule compliance among employees of the organization. Thus, we reasoned that the ethical behaviour of the organization (rather than its financial performance or efficiency) contributes to perceived organizational morality and pride, which in turn raise employee satisfaction, organizational commitment, and compliance. The validity of this reasoning was tested in a series of studies among different samples of employees working in a range of organizations.

Ellemers, Kingma, Van den Burgt, and Barreto (2011) asked employees in a variety of work contexts to indicate their evaluations of and attitudes towards their own organization. This work was done in the context of a broader research tradition on organizational behaviour, in which a social identity approach provides added value in understanding the work attitudes and behaviours of individual employees (e.g., Ashfort \& Mael, 1989; Haslam \& Ellemers, 2005; Hogg \& Terry 2000). Work in this research tradition tends to address work satisfaction and commitment to work teams and organizations as relevant outcome variables, 
as these related to the motivated behaviour of individual employees, such as the willingness to engage in discretionary efforts on behalf of the work team or organization (e.g., Ellemers, 2001; Ellemers, De Gilder, \& Haslam, 2004; Haslam \& Ellemers, 2005).

A first study (Ellemers et al., 2011, Study 1) examined the relation between perceived organizational morality on the one hand, and organizational commitment and work satisfaction on the other. Based on Tyler's (1999) social identity model of cooperation with the organization, the perceived value of the organization was thought to elicit feelings of organizational pride, which in turn should determine the tendency of employees to report feelings of attachment to the organization in the form of positive job attitudes such as satisfaction and commitment. To assess the role of perceived organizational morality as a potential source of group value (Leach et al., 2007), we addressed a convenience sample consisting of employees in the Netherlands $(\mathrm{N}=126)$, through a consultancy firm offering advice for organizations on possible Corporate Social Responsibility activities. Participants working at five different organizations were asked to indicate in an internet questionnaire to what extent they considered their organization to be honest, sincere, and trustworthy. Subsequently, they were asked whether they were proud to work for their organization, and indicated their level of affective organizational commitment and work satisfaction on rating scales. Structural equation modelling revealed that differences in perceived morality of one's organization were strongly related to differences in employee's attitudinal responses to the organization. That is, perceived organizational morality directly related to pride in organization and - through pride - showed an indirect relation with affective commitment to the organization and work satisfaction (see Figure 1). Alternative causal order models (e.g., in which employee attitudes or pride were examined as possible predictors of perceived organizational morality) fit the data less well.

A second study (Ellemers et al., 2011; Study 2) aimed to uncover potential antecedents of perceived organizational morality among a larger sample of workers in a 
specific organization $(\mathrm{N}=649)$. A range of organizational activities indicating Corporate Social Responsibility (CSR; Basu \& Palazzo, 2008; Wood, 1991) were listed to assess the extent to which this organization was perceived to display ethical behaviour (e.g., by refraining from making false promises to customers), to be involved with the local community, or to show concern for the environment. Such activities have been found to covary with organizational attractiveness (Schmidt, Albinger, \& Freeman, 2000) and reputation (Turban \& Greening, 1997). Accordingly, Ellemers et al. (2011, Study 2) investigated whether perceived engagement of the organization in specific CSR activities induces perceptions of organizational morality and impacts upon employees' attitudes relevant to work motivation. The results of this study confirmed that perceived engagement of the organization in CSR activities contributes to perceptions of organizational morality. In this context, organizational displays of ethical behaviour (e.g., towards customers) was more strongly related to perceived organizational morality than community involvement or environmental awareness. More importantly, perceived organizational morality mediated the effect of CSR activities on employees' affective commitment to the organization and job satisfaction - work attitudes that are relevant to the discretionary motivation of employees.

A potential drawback of this research was that the context of CSR activities conveying the interest of the researchers in organizational moral behaviour - was made explicit as the focus of the survey. This was not the case in another study, which was based on an ongoing large scale annual survey in a worldwide operating financial service organization (Ellemers \& Boezeman, under review). Through secondary analyses of this survey, Ellemers and Boezeman constructed indicators of perceived competence of the organization (organizational performance relative to other organizations, and internal efficiency of the organization) as well as of the perceived morality of the organization (integrity of organizational practices and behaviours of others in the organization). These were related to measures of work satisfaction and employee compliance: the willingness of 
individual workers to adhere to and enforce rules and regulations of the organization.

This analysis relied on pre-existing data that were collected by the organization to develop their HR policy - not for scientific research. Hence, the measures that were available were not ideally suited to assess the theoretical constructs or interest. Furthermore, even though surveys were taken at different points in time, different numbers and sub-samples of employees were surveyed each year, making it impossible to trace longitudinal developments over time. Nevertheless, the same pattern of results consistently emerged in responses from different samples of middle managers in this organization, even though they were working in a range of job types (operations, information technology, sales), in different parts of the world and surveyed at different points in time (Year 1: N=359; Year 2: N=4760; Year 3: $\mathrm{N}=7579$ ). Across the board, perceived organizational morality had an incremental value in predicting pride in the organization and employee satisfaction, above and beyond the impact of organizational competence. Furthermore, perceived organizational morality emerged as the only reliable predictor of employee compliance, showing regression weights between .30 and .45. Here too, reverse causal modelling (in which employee satisfaction or compliance were examined as potential predictors of perceived organizational morality) fit the data less well.

Thus, the evidence for the importance of morality for people's social identities extends beyond experimental findings obtained under artificially created conditions. Among different samples of workers working in a large variety of work contexts, perceptions of organizational morality were found to play a key role in predicting pride in the organization and organizational attachment. Moreover, activities and perceptions indicating the morality of the organization reliably predicted the job attitudes of individual employees relevant to work motivation and work performance. It is important to note that organizational morality was the primary predictor of employees' job attitudes, and emerged above and beyond the effects of organizational competence, even in a work context where competence clearly matters.

\subsection{Group norms and behavioural choices}


Whereas these studies among employees in different organizations yield results in line with our reasoning, the data available to us were correlational, making it difficult to draw unambiguous conclusions about the causality of the observed relations. This is why we more specifically examined the impact of morality on intragroup behavioural regulation, in a series of experiments. In all these experiments we presented participants with relevant group norms conveying approval of specific behaviours. We compared the impact of the same group norms, depending on whether behaviour in line with these norms was said to indicate superior competence or morality (i.e., someone who behaves in this way is considered smart/moral by the group). The general aim of these studies was to examine whether the importance of morality for individuals' collective self-concept also implies that they are more inclined to adhere to group norms when these refer to shared moral judgments.

A first series of studies, conducted with both artificially created and natural groups (Ellemers, Pagliaro, Barreto, \& Leach, 2008), examined the role of moral group norms on the behaviour of individual group members (in this case, the willingness to work at group instead of individual - status improvement). In previous work on the influence of group norms on group members' behaviour, individuals were usually led to believe that a general norm established which behaviour was valued by other group members (e.g., Barreto \& Ellemers, 2000; Jetten, Postmes \& McAuliffe, 2002; McAuliffe, Jetten, Hornsey, \& Hogg, 2003). This series of studies adapted the procedure employed by Barreto and Ellemers (2000) to manipulate group norms - i.e., providing bogus feedback on the right way to behave, allegedly derived from a previously interviewed sample of ingroup members - by additionally specifying whether the normative behaviour was seen by the group as attesting to the individual's morality or to the competence of the individual. That is, a comparison was made between morality-based group norms - suggesting that individuals should behave in a given way because it is the moral thing to do - with competence-based group norms suggesting that individuals should behave in a given way because it is the smart thing to do. 
Thus, participants were presented with group norms defined in terms of morality or competence considerations, to examine the differential effectiveness of these two types of norms, while the behaviour approved by these norms remained the same. The central prediction tested in this series of studies was that morality norms should have a greater impact on individual behavioural choices than competence norms. In this case, the focal behavioural choice was whether members of a low-status group decided to pursue individual or group status improvement, depending on the norm prescribed by other group members. The specific group norm was manipulated by means of bogus feedback in which the focus of the normative behaviour was counterbalanced. That is, participants were led to believe that their fellow in-group members considered individual or group status improvement as desirable, either because it is the moral or the competent thing to do. The primacy of morality over competence norms was not only investigated by assessing the extent to which people adapt their behaviour to these norms, but also by assessing how much time group members take to decide how to behave. If moral norms constitute such a powerful guideline for individual behaviour, then norms referring to moral judgments (rather than competence judgments) should more quickly and easily resolve the dilemma members of low-status groups face when deciding between individual and group status improvement.

A first study in this series (Ellemers et al., 2008, Study 1, N = 89) tested participants in a laboratory situation, where they were working on a personal computer. Their responses were obtained after orthogonally manipulating whether group norms referred to competence or morality judgments, and whether these suggested that group or individual status improvement was favoured by the group. Participants in this study were divided into groups, by means of a bogus "associative thinking" task (Doosje, Spears, \& Koomen, 1995; see also, Barreto \& Ellemers, 2000). Then they performed a group task, after which low group status was induced based on false task performance feedback. Subsequently, participants were told that a second task would follow to investigate how individual and group performance could 
be optimized. This task consisted of a series of organizational problems. However, on each trial participants had to decide whether they wanted to be tested individually or with their group. It was stressed that participants could either decide to contribute to their individual self-improvement (by deciding to be tested individually) or to the improvement of the group (by deciding to be tested as a group).

In-group norms were induced by informing participants how their fellow in-group members evaluated those who pursue individual vs. group status improvement. In the morality norm condition, in-group members were said to evaluate one strategy of status improvement as more moral and the other strategy as less moral. In the competence norm condition, in-group members were said to evaluate one strategy of status improvement as more "smart" and the other as more "stupid." Then participants' decisions to adopt a strategy of (individual vs. group) status improvement were assessed, and the decision latencies were monitored to be able to examine the time needed to decide whether or not follow the group norm.

Results of this first study revealed that participants were more likely to go along with the norm to pursue group status improvement when this norm was described in terms of morality rather than competence (see Table 4). The greater impact of morality rather than competence norms was also evident from participants' response latencies. As hypothesised participants took less time to decide on a strategy of status improvement when this was advocated by a morality norm rather than a competence norm. They quickly decided to follow the moral group norm, even when the strategy prescribed by the norm was in conflict with personal gains. This was different in the competence norm condition, where participants showed evidence of a decision delay (indicating a decisional dilemma) when the norm advocating group status improvement was in contrast with personal gains.

A subsequent study (Ellemers et al., 2008, Study 2, $\mathrm{N}=123$ ) was designed to more directly compare the relative impact of morality vs. competence norms against each other. 
Whereas participants in Study 1 either received information about what the group considered moral or about what the group considered competent, in this second study participants were simultaneously provided with information about the group's evaluation of different status improvement strategies both in terms of morality and competence. Thus, in some conditions the group approved of a particular strategy as being both moral and competent, and disapproved the opposing strategy as being immoral and incompetent (while counterbalancing the content of approved behaviour as being either individual or collective status improvement). In other conditions, the morality and competence norms diverged in advocating opposite strategies for status improvement (e.g., when the group considered individual status improvement to be smart but immoral). This created a trade-off in which the decision to follow a particular strategy - because it was approved by the group as being moral - would at the same time imply going against what the group considered competent, or vice versa. If it is true that moral judgments represent the most powerful guideline for intragroup behavioural regulation, participants should follow the moral norm even when this decision implies that they will be considered less competent by their group.

Results of this second study again showed that moral norms have a greater impact on the behaviour of individual group members than competence norms. Even though both types of norms influenced the behavioural decisions group members made, the effect of the moral norm was much stronger (partial eta squared $=.40$ ) than the effect of the competence norm (partial eta squared $=.04$ ). Moreover, participants' decision latencies indicated that morality norms provoke less of a decisional dilemma than competence norms, in that participants quickly decided to go along with the moral norm, regardless of how this would reflect on their perceived competence. This further confirmed that people attach more importance to morality norms than to competence norms in making behavioural choices.

Results of a third study in this series (Ellemers et al., 2008; Study 3, N = 100), further confirmed these findings with a different methodology, examining members of a natural 
group namely inhabitants of Southern Italy. Through a paper-and-pencil procedure, a sample of Southern Italians was asked to anonymously complete a questionnaire regarding employment in the South of Italy. Low ingroup status was induced by informing participants that a previous survey conducted by the National Institute for Statistics - comparing employment opportunities in different areas of Italy - had demonstrated that the economic situation was relatively unfavourable in the South of Italy. Subsequently, participants were informed that this prior survey had focused on two different ways in which people may deal with this difference in opportunities, namely by improving their personal position or by aiming to redress the disadvantageous employment conditions in the South more generally. Different group norms were then induced by indicating how other inhabitants from the South of Italy had evaluated these different strategies in a prior survey, in terms of morality and competence. For instance, participants were informed that personal position improvement was considered as smart, but also as immoral, or vice versa. Results of this study again confirmed that only the moral norm provided by the group affected participants' choice of strategy, while evaluating a particular behaviour as being competent or incompetent had no significant effect on participants' preferences for one strategy or the other.

\subsection{Moral norm adherence and intragroup respect}

The studies reviewed in the previous section extend prior research that showed that moral judgments can be more important than competence ratings in the evaluation of others (e.g., Skowronski \& Carlston, 1987), by showing that group members are more willing to comply with moral group norms than with norms otherwise framed. This suggests that it is also important for the self to be seen as moral by other members of an in-group. If this is indeed the case, adhering to moral norms should be considered the best way to be a 'good' group member, as a way to ensure individual inclusion and centrality in the group. The validity of this reasoning was examined in a series of studies asking participants to indicate how they experienced being evaluated by other group members, depending on whether these 
evaluations referred to their competence or their morality (Pagliaro, Ellemers, Barreto, \& Di Cesare, in preparation). In these studies we asked participants to consider how other members of their group would think of them if they were to display moral or immoral behaviour (indicating honesty, sincerity or trustworthiness) or if they were to behave in ways indicating their (lack of) competence, intelligence or skill.

The first study in this series (Study 1, $\mathrm{N}=126$ ) asked research participants to indicate for different evaluative judgments how pervasive they considered these to be, and to what extent each of these judgments would predict the respect received from other ingroup members. Results revealed that people consider moral evaluations by other ingroup members as more pervasive and as more consequential for the amount of respect they expect to receive from the ingroup. The second study (Study 2, N =299) replicated these results and additionally revealed that participants thought that displays of immoral behaviour would be more consequential for their long term image in the group than displays of incompetent behaviour. A third study (Study 3a, N = 138) further revealed that participants were prepared to engage in more effort to repair and justify their immoral (compared to their moral) behaviour towards their own group of friends, while judgments of their incompetent vs. competent behaviours did not yield differential reparation efforts. A fourth study (Study 3b, $\mathrm{N}=99$ ) demonstrated that there was no similar evidence of increased motivation to repair and justify immoral behaviour when this behaviour was observed and evaluated by others outside the group of friends, who were not considered self-relevant.

A further study (Study 4, N = 156), crossed the valence of ingroup judgments with the dimensions on which these judgments were made. This time, participants were asked to indicate how they would respond if their close friends would evaluate them positively or negatively in terms of their morality or competence. Results of this study again confirmed that moral judgments were seen as more pervasive than competence judgments. Furthermore, even though participants anticipated receiving more respect from the ingroup after a positive 
than after a negative evaluation, this effect was more pronounced for judgments pertaining to their morality than for judgments of their competence. Due to the greater perceived pervasiveness, participants subsequently indicated a greater willingness to invest effort to justify and repair their behaviour when they had been evaluated in terms of morality rather than competence. A final study (Study 5, N = 321) further corroborated these effects, and additionally revealed that the anticipated level of intra-group respect relates to stress and coping appraisals which in turn explain the willingness of individuals to engage in attempts to repair their image as a moral group member. That is, we found that a negative moral evaluation stemming from the ingroup lowers the level of anticipated ingroup respect. A series of mediation analyses subsequently showed that as a consequence of this, individuals report experiencing higher levels of situation-related stress and at the same time indicate perceiving their abilities to cope with the situation to be decreased. Both the enhanced stress and the reduced coping appraisals in turn predicted the individual's increased willingness to invest effort to justify and repair their behaviour.

Together these studies indicate that people are particularly concerned about appearing moral to other ingroup members, and are motivated to behave in ways that secure their standing in the group as a moral group member. If so, then this should have implications for the extent to which individuals adhere to group norms, as a function of whether or not these are perceived to be diagnostic of morality. Within groups, the pressure to be moral should be greater than the pressure to be competent, because the endorsement of diverging moral values in the group is experienced as more problematic for groups than diversity in competencies (Kouzakova, Ellemers, Harinck, \& Scheepers, in press). This is due to the fact that moral issues tend to be seen as self-identifying, and non-negotiable (Fiske \& Tetlock, 1997), causing lack of tolerance for those who adhere to different moral values (Skitka, Bauman, \& Sargis, 2005; Turiel, 1983). Accordingly, interpersonal differences in moral values have been found to reduce the desire for social interaction (Haidt, Rosenberg, \& Hom, 2003; Wainryb, 
Shaw, Laupa, \& Smith, 2001). As a result, deviance from moral values endorsed by the ingroup should be problematic for individual group members, who run the risk of jeopardizing their inclusion in the group. Conversely, compliance with shared moral values communicates that the individual is motivated to fit in and respects the behavioural guidelines proposed by other ingroup members (Ellemers \& Jetten, 2013). As a result, group members should anticipate that enacting moral norms provides a way to earn respect and acceptance from other ingroup members, while being aware that they might elicit social sanctions, in the forms of ridicule or ostracism when they transgress these norms (Fry, 2006; Sleebos, Ellemers, \& de Gilder, 2006; Smith \& Tyler, 1997; Tyler \& Lind, 1992; see also Tafarodi \& Milne, 2002).

This prior work led to the prediction that the effect of moral norms on the behaviour of individual group members is driven by the notion that this has more profound social identity implications than adherence to competence norms (Pagliaro et al., 2011; see also Rodriguez Mosquera et al., 2002; Schwartz, 1992). Two studies were conducted to test these predictions. Both were carried out among inhabitants of Southern Italy, and followed a design similar to the study by Ellemers et al. (2008, Study 3). The first study (Pagliaro et al., 2011, Study $1, N=82$ ) aimed to compare the effects of morality vs. competence based group norms on the behaviour of individual group members. Again, participants were first informed about the low status of their ingroup compared to inhabitants of Northern Italy, and provided with bogus results from a prior survey allegedly conveying morality and competence based group norms. However, this time participants were asked to indicate how they anticipated other members of their group to respond when they opted for the normative (vs. counter-normative) strategy, that is, when they behaved in line with what the group norm advocated. Specifically, participants estimated whether (counter-) normative behaviours would earn them respect from other ingroup members in terms of being included and valued as a group member (Sleebos et al., 2006; Smith \& Tyler, 1997; Tyler \& Lind, 1992). Then, participants indicated 
their willingness to invest effort in different strategies (i.e., individual and group status improvement strategies) that had allegedly been rated as normative or counter-normative by other members of their group.

Results of this study revealed that participants' willingness to invest in a particular strategy only depended on whether or not it was described as the group's moral norm (see Table 5). This was regardless of the specific status improvement strategy that was advocated by the group (individual or collective status improvement), and emerged on a variety measures that were used to assess their behavioural preferences. Furthermore, this effect of moral norms on the behaviour of individual group members' behaviour was mediated by anticipated ingroup respect (see Figure 2). That is, both when the group norm prescribed individual status improvement and when the norm prescribed collective status improvement, participants anticipated being more included and more valued as a group member when opting for the strategy that was considered moral by other ingroup members, and this anticipation in turn determined their behavioural choices. This is in line with our reasoning that people attach more importance to moral rather than competence group norms due to the special role of morality for people's social identities. The effectiveness of moral norms regardless of the strategy these prescribed allows for the exclusion of alternative explanations in terms of intra-group interdependence or instrumentality of cooperative behaviour in groups. Indeed, the fact that participants also went along with moral group norms that advocated individualistic behaviour indicates that such norms have a specific identitydefining function for the group and its members, rather than just constituting a tool to suppress selfish behaviour.

A second study using this paradigm was conducted to provide further evidence that the tendency to behave in line with moral norms actually stems from group-based social identities, instead of reflecting a more generic desire for (moral) social approval (Pagliaro et al., 2011, Study 2, N = 69). This study compared the effect of moral norms stemming from 
the ingroup with those stemming from a higher status outgroup. Thus, a sample of Southern Italians were simultaneously presented with information allegedly conveying ingroup (South of Italy) as well as outgroup (North of Italy) norms, with both groups either advocating the same strategy or ingroup and outgroup norms stating opposing preferences, depending on experimental conditions. Again anticipated ingroup respect and participants' own choice of a strategy to improve their social standing were assessed.

The results from this study revealed that the decisive factor in the effectiveness of moral norms is the consensus within the ingroup about what is morally appropriate. That is, participants in this study responded to ingroup norms in the same way as in Study 1. Again, moral ingroup norms influenced group members' behavioural choices because participants saw this as a way to earn respect from other ingroup members. However, no comparable effects were observed when identical moral norms were communicated by the outgroup. This further illustrates that the tendency to follow moral norms relates to participants' social identity concerns, rather than reflecting a more general desire to be positively evaluated in moral domains, and underlines the significance of distinct group identities and the importance of ingroup respect in this process.

\section{CONCLUSION AND FUTURE DIRECTIONS}

In this review we have considered the implications of moral judgments within groups for the behavioural regulation of individual group members. This complements existing approaches that either address individual-level moral decision making, or consider how people respond when they are asked to consider the possibility that their group has behaved immorally. The social identity approach we have proposed here makes clear that - in addition to generic and universal moral norms - specific behavioural guidelines may be elevated to the level of moral group standards that come to define how the group is different from other groups, and prescribe what is the 'right' way for group members to behave. In support of this 
analysis, we have reviewed results from a recent program of research, revealing the importance of morality for group identification and pride, which in turn impacts on the willingness of individual group members to adhere to moral group norms.

When considering the social implications of morality, we highlighted how morality is identity defining (Ellemers \& Van den Bos, 2012). People prefer to identify with moral (vs. competent or sociable) groups, and they are more proud to belong to such groups (Leach et al., 2007). This is also the case in organizational contexts where perceptions of organizational morality elicit pride in the organization which, in turn, determine organizational commitment and employee work satisfaction (Ellemers et al., 2011). Accordingly, the perceived morality of an organization is more important than its perceived competence in predicting the likelihood that individual employees display job satisfaction and are willing to comply with organizational rules and regulations (Ellemers \& Boezeman, under review). Given that group leaders are preferred when they embody core group values (Haslam, Reicher, \& Platow, 2011), leadership endorsement also relies on perceived leader morality, and more so than on perceived leader competence. In addition, when team members believe their leader is prototypical of the group, they assume the leader is moral, rather than immoral, demonstrating the close relation between perceived leader morality and prototypicality (Barreto et al., 2012).

These results demonstrate the fundamental role of morality in defining who we are and where we belong. The more individuals psychologically identify with and value the ingroup, the more they should be motivated to show they are "good" group members. As a consequence, since morality is central to group's distinct identity, an important way to acquire respect within the group is to behave in a manner that the ingroup defines as morally right. Further consideration of this group dynamic function of morality allows for the examination of the role of morality on the intra-group regulation processes as a source of group influence which affects behavioural regulation within groups (see also Aquino \& Reed, 
2002). In line with the reasoning we propose, the research discussed in this review consistently shows that people are particularly concerned about the group's evaluation of their morality rather than about the group's evaluations of their competence and are more motivated to behave in ways that demonstrate their morality to the ingroup (Pagliaro et al., in preparation). As a result of this process, individual group members are more likely to adhere to group norms when such norms are seen to convey the moral (vs. competence) evaluations of other ingroup members (Ellemers et al., 2008; Pagliaro et al., 2011). The effect of moral norms on individuals' behaviour is guided by the anticipation that pro-normative behaviour allows individuals to earn respect from other ingroup members (Pagliaro et al., 2011). An important consequence of this process is that the impact of moral group norms occurs regardless of the specific (e.g., individualistic vs. collectivistic) behaviour prescribed by the norm. This allows us to understand that people sometimes persist in behaving in ways that may be considered as immoral, due to group pressure. As long as the moral norms of the group condone or prescribe such behaviour individuals will be motivated to display acts that can earn them respect as a 'good' and 'proper' group member. In this context, it is also noteworthy that individuals do not adapt their behavioural choices to moral norms when these are conveyed by others who are not seen as relevant to the self (e.g. outgroup members). This last result reminds us that there is scope in going beyond a theorization of morality as a generic tendency to suppress selfish behaviour. Indeed, it highlights the added value of considering the group-dynamic and social identity implications of group-specific moral judgments that help understand the role of morality and moral judgments for the regulation of individual behaviour in group contexts.

This approach to morality emphasizing intra-group dynamics aims at complementing previous understandings of morality, as well as raising new and intriguing questions. Considering specific social-regulatory functions of morality seems an important starting point to develop new directions for future research. For instance, now that we have determined that 
morality helps individuals to define who they are and the groups or organizations they want to belong to, it would be interesting to investigate the reverse process. That is, future research might reveal specific circumstances under which individuals are prone to define themselves in terms of shared moral values, and examine how they respond to other ingroup or outgroup members who either challenge or validate their morality. Moreover, given the centrality of morality for people's sense of self and social identity, it would be of interest to investigate whether and how people invoke claims of superior ingroup morality as a collective strategy to improve or maintain a positive social identity.

Further consideration of the group-dynamic function of moral judgments also raises additional questions of interest. For instance, it seems useful to reconsider some wellestablished phenomena in the light of the recent findings reviewed here. Although there is abundant evidence in the literature attesting to the impact of social norms on individual behavioural choices, we have shown in this review that adherence to norms that have implications for one's perceived morality is more pronounced than adherence to norms that are consequential for one's perceived competence. Would the dimension of evaluation also moderate the management of deviance either by helping group members improve their behaviour or by excluding them from the group? The present work suggests that counternormative behaviour should elicit more severe sanctions when this implies a moral violation. Thus, future research might establish whether a deviant ingroup member would be more likely to be punished whether he/she transgresses a moral dictate than when a different type of transgression takes place. However, it may also be that the perceived severity of the transgression in itself is already stronger when it occurs in a domain defined as moral. These and related questions might be pursued in future research.

In sum, additional questions remain, and future research can further advance our comprehension of the dynamics of morality. Nevertheless, the present review convincingly shows that considering the role of intra-group dynamics and group-based identities 
contributes to a better understanding of the importance of moral judgments. Indeed, considering morality in terms of its social functions, instead of focusing exclusively on the implications of specific moral guidelines for individual decision making, provides a new and exciting perspective on this important area of research. 


\section{REFERENCES}

Anderson, N. H., \& Sedikides, C. (1991). Thinking about people: Contributions of a typological alternative to associationistic and dimensional models of person perception. Journal of Personality and Social Psychology, 60, 203-217.

Aquino, K., \& Reed, A. (2002). The self-importance of moral identity. Journal of Personality and Social Psychology, 83, 1423-1440.

Ashfort, B. E., \& Mael, F. (1989). Social Identity Theory and the organization. Academy of Management Review, 14, 20-39.

Barreto, M., \& Ellemers, N. (2000). You can't always do what you want: Social identity and self-presentational determinants of the choice to work for a low-status group. Personality and Social Psychology Bulletin, 26, 891-906.

Barreto, M., Haslam, S. A., \& Kerridge, G. (2012). The importance of morality in leadership endorsement. Manuscript in preparation: University of Exeter.

Basu, K., \& Palazzo, G. (2008). Corporate social responsibility: A process model of sensemaking. Academy of Management Review, 33, 122-136.

Batson, C. D. (2008). Moral masquerades: Experimental exploration of the nature of moral motivation. Phenomenology and the Cognitive Sciences, 7, 51-66.

Batson, C. D., Kobrynowicz, D., Dinnerstein, J. L., Kampf, H. C., \& Wilson, D. W. (1997). In a very different voice: Unmasking moral hypocrisy. Journal of Personality and Social Psychology, 72, 1335-1348.

Batson, C. D., Thompson, E. R., \& Chen, H. (2002). Moral hypocrisy: Addressing some alternatives. Journal of Personality and Social Psychology, 83, 330-339.

Batson, C. D., Thompson, E. R., Seuferling, G., Whitney, H., \& Strongman, J. (1999). Moral hypocrisy: Appearing moral to oneself without being so. Journal of Personality and Social Psychology, 77, 525-537. 
Beauchamp, T. L. (2001). Philosophical ethics: An introduction to moral philosophy (3rd ed.). Boston: McGraw-Hill.

Boezeman, E., \& Ellemers, N. (2007). Volunteering for charity: Pride, respect, and Commitment of volunteer workers. Journal of Applied Psychology, 92, 771-785.

Brambilla, M., Rusconi, P. P., Sacchi, S., \& Cherubini, P. (2011). Looking for honesty: The primary role of morality (vs. sociability and competence) in information gathering. European Journal of Social Psychology, 41, 135-143.

Brambilla, M., Sacchi, S., Pagliaro, S., \& Ellemers, N. (in press). Morality and intergroup behaviour: Threats to safety and group image trigger responses to outgroup and ingroup members. Journal of Experimental Social Psychology, doi: 10.1016/j.jesp.2013.04.005

Brambilla, M., Sacchi, S., Rusconi, P.P., Cherubini, P., \& Yzerbyt, V.Y. (2012). You want to give a good impression? Be honest! Moral traits dominate group impression formation. British Journal of Social Psychology, 51, 149-166.

Čehajić-Clancy, S., Effron, D.A., Halperin, E., Liberman, V., \& Ross, L.D. (2011). Affirmation, acknowledgment of in-group responsibility, group-based guilt, and support for reparative measures. Journal of Personality and Social Psychology, 101, 256-270.

Cronin, T., Reysen, S., \& Branscombe, N. R. (2012). Wal-Mart's Conscientious Objectors: Perceived Illegitimacy, Moral Anger, and Retaliatory Consumer Behavior. Basic and Applied Social Psychology, 34, 322-335.

Cuddy, A. J. C., Fiske, S. T., \& Glick, P. (2008). Warmth and competence as universal dimensions of social perception: The Stereotype Content Model and the BIAS Map. In M. P. Zanna (Ed.), Advances in experimental social psychology (pp. 61-149). San Diego: Academic Press.

De Bruin, E. N. M., \& Van Lange, P. A. M. (1999). Impression formation and cooperative 
behavior. European Journal of Social Psychology, 29, 305-328.

De Bruin, E. N. M., \& Van Lange, P. A. M. (2000). What people look for in others:

Influences on the perceiver and the perceived on information selection. Personality and Social Psychology Bulletin, 26, 206-219.

De Waal, F. (1996). Good natured: The origins of right and wrong in humans and other animals. Cambridge, MA: Harvard University Press.

Does, S., Derks, B., \& Ellemers, N. (2011). Thou shall not discriminate: How emphasizing moral ideals rather than obligations increases whites' support for social equality. Journal of Experimental Social Psychology, 47, 562-571.

Does, S., Derks, B., Ellemers, N., \& Scheepers, D. (2012). At the heart of egalitarianism: How equality framing shapes cardiovascular challenge vs. threat in whites. Social Psychology and Personality Science, 3, 747-753.

Doosje, B., Spears, R., \& Koomen, W. (1995). When bad isn’t all bad: Strategic use of sample information in generalization and stereotyping. Journal of Personality and Social Psychology, 69, 642-655.

Ellemers, N. (2012). The group self. Science, 336, 848-852.

Ellemers, N. (2001). Individual upward mobility and the perceived legitimacy of intergroup relations. In J. T. Jost, \& B. Major (Eds.), The Psychology of Legitimacy (pp. 205-222). Cambridge: Cambridge University Press.

Ellemers, N., \& Boezeman, E.J., Integrity and compliance: How perceived organizational morality and competence of a financial service organization relate to employee compliance and work satisfaction. Manuscript under review

Ellemers, N., De Gilder, D., \& Haslam, S. A. (2004). Motivating individuals and groups at work: A social identity perspective on leadership and group performance. Academy of Management Review, 29, 459-478. 
Ellemers, N., De Gilder, D., \& Van den Heuvel, H. (1998). Career-oriented versus team-oriented commitment and behavior at work. Journal of Applied Psychology, 83, 717-730.

Ellemers, N., \& Haslam, S.A. (2011). Social identity theory. In: P. van Lange, A. Kruglanski, \& T. Higgins (Eds.). Handbook of theories of social psychology (pp. 379-398). London: Sage.

Ellemers, N., \& Jetten, J. (2012). The many ways to be marginal in a group. Manuscript under review.

Ellemers, N., Kingma, L., Van den Burgt, J., \& Barreto, M. (2011). Corporate Social Responsibility as a source of organizational morality, employee commitment and satisfaction. Journal of Organizational Moral Psychology, 1, 97-124.

Ellemers, N., Pagliaro, S., Barreto, M., \& Leach, C.W. (2008). Is it better to be moral than smart? The effects of morality and competence norms on the decision to work at group status improvement. Journal of Personality and Social Psychology, 95, 13971410.

Ellemers, N., Spears, R., \& Doosje, B. (2002). Self and social identity. Annual Review of Psychology, 53, 161-186.

Ellemers, N., \& van den Bos, K. (2012). Morality in groups: On the social-regulatory functions of right and wrong. Social and Personality Psychology Compass, 6, 878889.

Ellemers, N., \& Van Nunspeet, F. (in press). Moral accountability and prejudice control: Evidence from cardiovascular and EEG responses. In: B. Derks, D. Scheepers, \& N. Ellemers (Eds). The neuropsychology of prejudice and intergroup relations. New York: Psychology Press.

Ellemers, N., Van Nunspeet, F., \& Scheepers, D. (in press). It's all in the mind: How social identification processes affect neurophysiological responses. In: M. Mikulincer \& P. 
Shaver (Eds.), The mechanisms of social connection: From brain to group.

Washington, DC: American Psychological Association.

Epley, N., \& Dunning, D. (2000). Feeling "Holier Than Thou": Are Self-Serving Assessments Produced by Errors in Self- or Social Prediction? Journal of Personality and Social Psychology, 79, 861-875.

Fiske, S. T. (1980). Attention and weight in person perception: The impact of negative and extreme behaviour. Journal of Personality and Social Psychology, 38, 889-906.

Fiske, S. T., Cuddy, A. J. C., Glick, P., \& Xu, J. (2002). A model of (often) mixed stereotype content: Competence and warmth respectively follow from perceived status and competition. Journal of Personality and Social Psychology, 82, 878-902.

Fiske, A.P., \& Tetlock, P.E. (1997). Taboo trade-offs: Reactions to transactions that transgress the spheres of justice. Political Psychology, 18, 255-297.

Fry, D. P. (2006). Reciprocity: The foundation stone of morality. In: M. Killen, \& J. G. Smetana (Eds), Handbook of moral development (pp. 399-422). Mahwah, NJ: Lawrence Erlbaum.

Gert, B. (1988). A new justification of the moral rules. Oxford: Oxford University Press.

Giner-Sorolla, R. (2012). Judging passions: Moral emotions in persons and groups. European Monographs in Social Psychology. London: Psychology Press.

Haidt, J. (2001). The emotional dog and its rational tail: A social intuitionist approach to moral judgment. Psychological Review, 108, 814-834.

Haidt, J. (2008). Morality. Perspectives on Psychological Science, 3, 65 - 72.

Haidt, J., \& Graham, J. (2007). When morality opposes justice: Conservatives have moral intuitions that liberals may not recognize. Social Justice Research, 20, 98-116.

Haidt, J., \& Kesebir, S. (2010). Morality. In S. Fiske, D. Gilbert, \& G. Lindzey (Eds.), Handbook of Social Psychology, $5^{\text {th }}$ Edition (pp. 797-832). Hoboken, NJ: Wiley.

Haidt, J., Rosenberg, E., \& Hom, H. (2003). Differentiating diversity: Moral diversity is not 
like other kinds. Journal of Applied Social Psychology, 33, 1-36.

Haslam, S. A., \& Ellemers, N. (2005). Social identity in industrial and organizational psychology: Concepts, controversies and contributions'. In G. P. Hodgkinson \& J. K. Ford (Eds.), International Review of Industrial and Organizational Psychology, 20 (pp. 39-118). John Wiley and Sons, Chichester.

Haslam, S. A., \& Ellemers, N. (2011). Identity processes in organizations. In: Schwartz, S. J., Luyckx, K., Vignoles, V. L. (Eds). Handbook of identity theory and research, Volume 1, Structures and Processes (pp. 715-744). New York: Springer.

Hogg, M. A., \& Terry, D. J. (2000). Social identity and self-categorization processes in organizational context. Academy of Management Review, 25, 121-140.

Jetten, J., Postmes, T., \& McAuliffe, B. J. (2002). "We're all individuals": Group norms of individualism and collectivism, level of identification and identity threat. European Journal of Social Psychology, 32, 189-207.

Judd, C. M., James-Hawkins, L., Yzerbyt, V., \& Kashima, Y. (2005). Fundamental dimensions of social judgment: Understanding the relations between judgments of competence and warmth. Journal of Personality and Social Psychology, 89, 899-913.

Kohlberg, L. (1969). Stage and sequence: The cognitive-developmental approach to socialization. In D.A. Goslin (Ed.), Handbook of socialization theory and research (pp. 347-380). Chicago: Rand McNally.

Kouzakova, M., Ellemers, N., Harinck, F., \& Scheepers, D. (2012). The implications of value conflict: How disagreement on values affects self-involvement and perceived common ground. Personality and Social Psychology Bulletin, 38, 798-807.

Kouzakova, M., Harinck, F., Ellemers, N., \& Scheepers, D. At the heart of a conflict: Cardiovascular and self-regulation responses to value vs. resource conflicts. Paper under editorial consideration. 
Leach, C. W., Bilali, R., \& Pagliaro, S. (forthcoming). Groups and Morality. To appear in J. Simpson \& J. F. Dovidio (Eds.) APA Handbook of Personality and Social Psychology, Vol. 2: Interpersonal Relationships and Group Processes. Washington, DC: American Psychological Association.

Leach, C. W., Ellemers, N., \& Barreto, M. (2007). Group virtue: The importance of morality (vs. competence and sociability) in the positive evaluation of in-groups. Journal of Personality and Social Psychology, 93, 234-249.

Manstead, A. S. R. (2000). The role of moral norm in the attitude-behavior relationship. In D. J. Terry \& M. A. Hogg (Eds.), Attitudes, Behavior, and Social Context: The Role of Norms and Group Membership (pp. 11-30). Mahwah, NJ: Erlbaum.

Marques, J. M., Yzerbyt, V. Y., \& Leyens, J.-Ph. (1988). Extremity of judgments towards ingroup members as a function of ingroup identification. European Journal of Social Psychology, 18, 1-16.

Martijn, C., Spears, R., Van Der Pligt, J., \& Jakobs, E. (1992). Negativity and positivity effects in person perception and inference: Ability versus morality. European Journal of Social Psychology, 22, 453-463.

McAuliffe, B. J., Jetten, J., Hornsey, M. J., \& Hogg, M. A. (2003). Individualist and collectivist norms: When it's ok to go your own way. European Journal of Social Psychology, 33, 57-70.

Miron, A., Branscombe, N. R., \& Biernat, M. (2010). Motivated Shifting of Justice Standards. Personality and Social Psychology Bulletin, 36, 768-779.

Mlicki, P., \& Ellemers, N., (1996). Being different or being better? National stereotypes and identifications of Polish and Dutch students. European Journal of Social Psychology, 26, 97-114.

Monin, B., \& Jordan, A.H. (2009). The dynamic moral self: A social psychological perspective. In D. Narvaez \& D. K. Lapsley (Eds), Personality, Identity, and 
Character: Explorations in Moral Psychology (pp. 341-354). New York: Cambridge University Press.

Pagliaro, S. (2012). On the relevance of morality in social psychology: An introduction to a virtual special issue. European Journal of Social Psychology, 42, 400-405.

Pagliaro, S., Brambilla, M., Sacchi, S., D'Angelo, M., \& Ellemers, N. (in press). Initial impressions determine behaviours: Morality predicts the willingness to help newcomers. Journal of Business Ethics. DOI: 10.1007/s10551-012-1508-y

Pagliaro, S., Ellemers, N., \& Barreto, M. (2011). Sharing moral values: Anticipated in-group respect as a determinant of adherence to morality-based (but not competence-based) group norms. Personality and Social Psychology Bulletin, 37, 1117-1129.

Phalet, K., \& Poppe, E. (1997). Competence and morality dimensions of national and ethnic stereotypes: A study in six eastern-European countries. European Journal of Social Psychology, 27, 703-723.

Piaget, J. (1965). The moral judgment of the child. New York: Free Press.

Rai, T. S. \& A. P. Fiske (2011). Moral psychology is relationship regulation: Moral motives for unity, hierarchy, equality, and proportionality. Psychological Review 118, 57-75.

Reeder, G. D., \& Brewer, M. B. (1979). A schematic model of dispositional attribution in interpersonal perception. Psychological Review, 86, 61-79.

Reeder, G. D., \& Coovert, M. D. (1986). Revising an impression of morality. Social Cognition, 4, 1-17.

Reeder, G. D., Pryor, J. B., \& Wojciszke, B. (1992). Trait-behaviour relations in social information processing. In G. Semin \& K. Fiedler (Eds.) Language and social cognition (pp. 37-57). Beverly Hills, CA: Sage.

Rodriguez Mosquera, P. M., Manstead, A. S. R., \& Fischer, A. H. (2002). The role of honour concerns in emotional reactions to offences. Cognition and Emotion, 16, 143-163. 
Rothbart, M, \& Park, B. (1986). On the confirmability and disconfirmability of trait concepts. Journal of Personality and Social Psychology, 50, 131-142.

Schmidt Albinger, H., \& Freeman, S. J. (2000). Corporate social performance and attractiveness as an employer to different job seeking populations. Journal of Business Ethics, 28, 243-253.

Schwartz, S. H. (1970). Elicitation of moral obligation and self-sacrificing behavior: An experimental study of volunteering to be a bone marrow donor. Journal of Personality and Social Psychology, 15, 283-93.

Schwartz, S. H. (1992). Universals in the content and structure of values: Theoretical advances and empirical tests in 20 countries. In M. P. Zanna (Ed.), Advances in Experimental Social Psychology, (Vol. 25, pp. 1-65). New York, NY: Academic Press.

Skitka, L. J., Bauman, C. W., \& Sargis, E. G. (2005). Moral conviction: Another contributor to attitude strength or something more? Journal of Personality and Social Psychology, 88, 895-917.

Skowronski, J. J., \& Carlston, D. E. (1987). Social judgment and social memory: The role of cue diagnosticity in negativity, positivity, and extremity biases. Journal of Personality and Social Psychology, 52, 689-699.

Sleebos, E., Ellemers, N., \& De Gilder, D. (2006). The carrot and the stick: Affective commitment and acceptance anxiety as motives for discretionary group efforts by respected and disrespected group members. Personality and Social Psychology Bulletin, 32, 244-255.

Smith, H. J. \& Tyler, T. R. (1997). Choosing the right pond: The impact of group membership on self-esteem and group-oriented behavior. Journal of Experimental Social Psychology, 33, 146-170.

Subašić, E., Schmitt, M. T., \& Reynolds, K. J. (2011). Are we all in this together? Co- 
victimization, inclusive social identity and collective action in solidarity with the disadvantaged. British Journal of Social Psychology, 50, 707-725.

Tafarodi, R. W., \& Milne, A. B. (2002). Decomposing global self-esteem. Journal of Personality, 70, 443-483.

Tajfel, H., \& Turner, J.C. (1979). An integrative theory of intergroup conflict. In W.G. Austin \& S. Worchel (Eds.), The social psychology of intergroup relations (pp. 33-47). Monterey, C.A.: Brooks Cole.

Tarrant, M., Branscombe, N. R., Warner, R. H., \& Weston, D. (2012). Social identity and perceptions of torture: It's moral when we do it. Journal of Experimental Social Psychology, 48, 513-518.

Tomasello, M. \& Vaish, A., (2013). Origins of human cooperation and morality. Annual Review of Psychology, 64, 231-255.

Tooby, J. \& Cosmides, L. (2010). Groups in mind: The coalitional roots of war and morality. In: H. Hogh-Olesen (Ed.) Human morality and sociality. (191-234). New York: Palgrave Macmillan.

Trafimow, D., \& Trafimow, S. (1999). Mapping imperfect and perfect duties onto hierarchically and partially restrictive trait dimensions. Personality and Social Psychology Bulletin, 25, 686-695.

Turban D. B., \& Greening D. W. (1997). Corporate Social Performance and Organizational Attractiveness to Prospective Employees. Academy of Management Journal, 40, 658 -672 .

Turiel, E. (1983). The development of social knowledge: Morality and conventions. New York: Cambridge University Press.

Turiel, E. (2006). Thought, emotions, and social interactional processes. In: M. Killen, \& J.G. Smetana (Eds.). Handbook of moral development (pp. 7-35). Mahwah, N.J.: Lawrence Erlbaum. 
Turner, J. C. (1991). Social influence. Milton Keynes: Open University Press.

Tyler, T. R. (1999). Why people cooperate with organizations: An identity-based perspective. In R. I. Sutton \& B. M. Staw (Eds.), Research in Organizational Behavior: An annual series of analytical essays and critical reviews (pp. 210-246). Stanford: JAY Press.

Tyler, T. R. \& Lind, A. E. (1992). A relational model of authority in groups. Advances in Experimental Social Psychology, 25, 115-191.

Van Lange, P. A. M., \& Kuhlman, D. M. (1994). Social value orientations and impressions of a partner's honesty and intelligence: A test of the might versus morality effect. Journal of Personality and Social Psychology, 67, 126-141.

Van Lange, P. A. M., \& Liebrand, W. B. G. (1991). The influence of other's morality and own social value orientation on cooperation in the Netherlands and the U.S.A. International Journal of Psychology, 26, 429-449.

Van Leeuwen, F., Park, J.H., \& Penton-Voak, I.S. (2012). Another fundamental social category? Spontaneous categorization of people who uphold or violate moral norms. Journal of Experimental Social Psychology, 48, 1385-1388.

Van Nunspeet, F., Ellemers, N., Derks, B., \& Nieuwenhuis, S. (in press). Moral concerns increase attention and response monitoring during IAT performance: ERP evidence. Social, Cognitive and Affective Neuroscience. doi: 10.1093/scan/nss118

Van Nunspeet, F., Derks, B., Ellemers, N., \& Nieuwenhuis, S. (2013). Moral impression management: Evaluation by an ingroup member during a moral IAT enhances perceptual attention and response monitoring. Manuscript under editorial consideration.

Vonk, R. (1996). Negativity and potency effects in impression formation. European Journal of Social Psychology, 26, $851-865$.

Wainryb, C., Shaw, L. A., Laupa, M., \& Smith, K. R. (2001). Children's, adolescents' and young adults' thinking about different types of disagreements. Developmental 
Psychology, 37, 373-386.

Willis, J., \& Todorov, A. (2006). First impression: Making up your mind after a 100-Ms exposure to a face. Psychological Science, 17, 592-598.

Winston, J. S., Strange, B. A., O’Doherty, J., \& Dolan, R. J. (2002). Automatic and intentional brain responses during evaluation of trustworthiness of faces. Nature Neuroscience, 5, 277-283.

Wojciszke, B. (2005). Morality and competence in person- and self-perception. European Review of Social Psychology, 16, 155-188.

Wojciszke, B., Bazinska, R., \& Jaworski, M. (1998). On the dominance of moral categories in impression formation. Personality and Social Psychology Bulletin, 24, 1251-1263.

Wood, D. J. (1991). Corporate social performance revisited. Academy of Management Review, 16, 691-718. 
Table 1: School teachers' mean emotional responses and behavioral approach intentions towards a new principal described in terms of morality (high vs. low) and competence (high vs. low). Standard deviations are provided within brackets (Pagliaro et al., in press; $\mathrm{N}=79$ )

Morality

$\begin{array}{lll}\text { High } & 5.84(0.87) & 5.29(1.17) \\ \underline{\text { Low }} & 4.30(1.33) & 3.60(1.34)\end{array}$

Note: 0 (not at all) - 7 (very much).

(Source: Pagliaro, S., Brambilla, M., Sacchi, S., D'Angelo, M., \& Ellemers, N. (in press).

Initial impressions determine behaviours: Morality predicts the willingness to help newcomers. Journal of Business Ethics. DOI: 10.1007/s10551-012-1508-y. Reprinted with permission from Springer Science+Business Media B.V.) 
Table 2: Implicit bias (IAT D-scores) towards women with or without headscarves, depending on whether the IAT is presented as indicating participant's morality or competence. Lower D-scores indicate less implicit bias. Standard deviations are provided within brackets (adapted from Van Nunspeet, F., Ellemers, N., Derks, B., \& Nieuwenhuis, S. (in press). Moral concerns increase attention and response monitoring during IAT performance: ERP evidence. Social, Cognitive and Affective Neuroscience. doi: 10.1093/scan/nss118).

Test of morality 
Table 3: Group pride and perceived ingroup variability reported by students of Leiden University as a function of manipulations of the morality (high vs. low) and competence (high vs. low) of the university (Study 4; $N=96$ ), or the morality (high vs. low) and sociability (high vs. low) of the university (Study $5 ; \mathrm{N}=87$ ). Standard deviations are provided within brackets (Adapted from: Leach, C. W., Ellemers, N., \& Barreto, M. (2007). Group virtue: The importance of morality (vs. competence and sociability) in the positive evaluation of in-groups. Journal of Personality and Social Psychology, 93, 234-249).

$\underline{\text { Study } 4}$

$\begin{array}{llll}\text { Morality } & \text { High } & 4.76(1.18) & 3.85(1.29) \\ & \underline{\text { Low }} & 4.39(1.15) & 3.52(1.49)\end{array}$

$\underline{\text { Study } 5}$

$\begin{array}{llll}\text { Morality } & \underline{\text { High }} & 5.16(0.80) & 4.34(1.37) \\ & \underline{\text { Low }} & 4.73(0.86) & 3.85(1.44)\end{array}$

Note: 0 (not at all) - 7 (very much). 
Table 4: Choice of status improvement strategies (work for group vs. self) and decision latencies as function of ingroup norms labeling group status improvement as moral vs. competent (Study 1; $\mathrm{N}=89$ ); and as a function of moral norms (moral approval vs. disapproval) compared to competence norms (competence approval vs. disapproval) in experimental (Study 2; N = 123) and natural (Study 3; N = 100) groups. Standard deviations are provided within brackets (Adapted from: Ellemers, N., Pagliaro, S., Barreto, M., \& Leach, C.W. (2008). Is it better to be moral than smart? The effects of morality and competence norms on the decision to work at group status improvement. Journal of Personality and Social Psychology, 95, 1397-1410).

Study 1

Moral Norm

Competence Norm

$\underline{\text { Study } 2}$

$\underline{\text { Moral Norm }}$

$\underline{\text { Study } 3}$

\begin{tabular}{|c|c|c|}
\hline & Approval & Disapproval \\
\hline Moral Norm & $6.76(1.71)$ & $5.89(2.39)$ \\
\hline Competence Norm & $6.02(2.22)$ & $6.61(2.00)$ \\
\hline
\end{tabular}

$\underline{\text { Response Latency (in sec) }}$

$4.22(1.96)$

$5.16(2.75)$

$\underline{\text { Choice to work for group }^{\mathrm{a}} \quad \underline{\text { Response Latency (in sec) }}}$

$\underline{\text { Approval Disapproval }}$ Approval Disapproval

$3.28(1.40) \quad 1.13(0.67) \quad 3.88(1.87) \quad 4.05(1.83)$

$2.50(1.70) \quad 1.96(1.63) \quad 4.07(1.74) \quad 3.87(1.96)$

Choice to work for group ${ }^{\mathrm{b}}$

Approval Disapproval

Note: ${ }^{\mathrm{a}} 0$ (always individual status improvement) - 5 (always group status improvement).

${ }^{\mathrm{b}} 0$ (absolutely not) - 5 (absolutely). 
Table 5: Norm adherence and anticipated ingroup respect as a function of ingroup norms conveying moral approval vs. disapproval compared to competence approval vs. disapproval (Study $1 ; \mathrm{N}=82$ ), or compared to outgroup norms indicating moral approval vs. disapproval (Study 2; $\mathrm{N}=69$ ). Standard deviations are provided within brackets (Pagliaro et al., 2011).

$\underline{\text { Study } 1}$

Ingroup Norm
Moral Approval
Moral Disapproval

Norm Adherence

$6.98(1.59)$

$4.86(2.19)$

Anticipated Ingroup Respect

$6.05(2.17)$

$3.29(1.81)$

$\underline{\text { Study } 2}$

Norm Adherence

$7.46(1.06)$

$6.12(1.76)$

Anticipated Ingroup Respect

$6.98(1.39)$

$2.71(1.12)$

Note: 1 (absolutely not) -9 (absolutely).

(Source: Pagliaro, S., Ellemers, N., \& Barreto, M. (2011). Sharing moral values: Anticipated in-group respect as a determinant of adherence to morality-based (but not competence-based) group norms. Personality and Social Psychology Bulletin, 37, 1117-1129. by $<<$ SAGE Publications Ltd. $>>/<<$ SAGE Publications, Inc. $>$, All rights reserved. ( $)$ 2011) 
Figure 1. The effect of perceived organizational morality, through pride in the organization, on affective commitment and work satisfaction of organizational employees. Results of Structural Equation Modeling (Ellemers et al., 2011, Study 1; $\mathrm{N}=126$ )

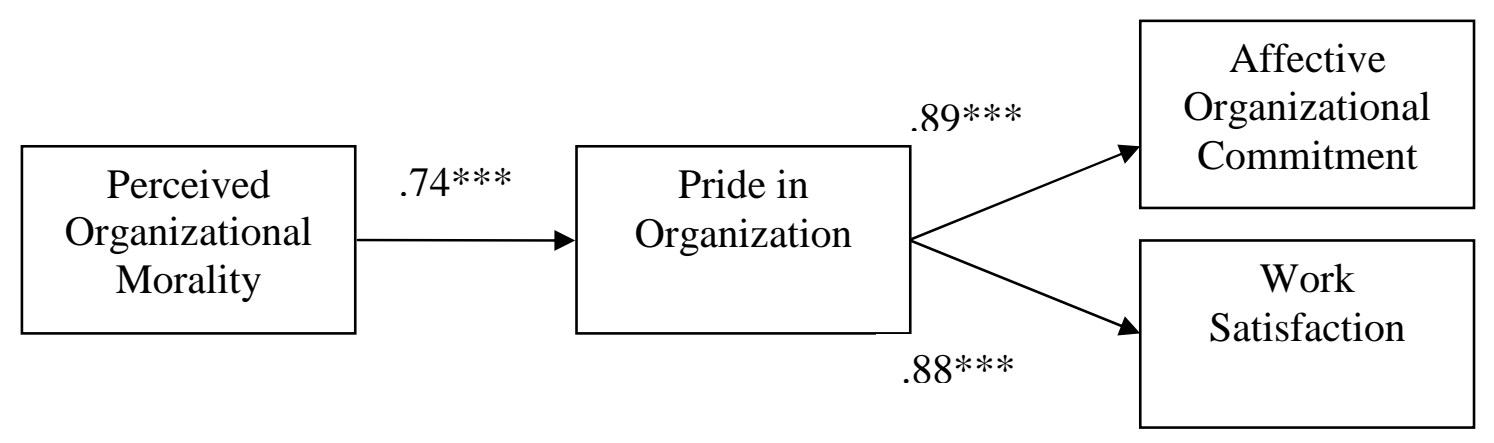

Note: $* * * p<.001$ (Fit indices: $\chi^{2}=80.67, N=126$, $\mathrm{df}=41$; NNFI $=.95 ; \mathrm{CFI}=96$; RMSEA $=.09 ;$ AIC $=-1.34)$.)

(Reprinted from: Journal of Organizational Moral Psychology, 1. Corporate Social Responsibility as a source of organizational morality, employee commitment and satisfaction, 97-124; copyright (2011). Ellemers, N., Kingma, L., Van den Burgt, J., \& Barreto, M.) 
Figure 2. Anticipated Ingroup Respect mediates the effect of moral ingroup norms on willingness to invest in (collective and individual) strategies for status improvement (Pagliaro et al., 2011, Study 1; N = 82).

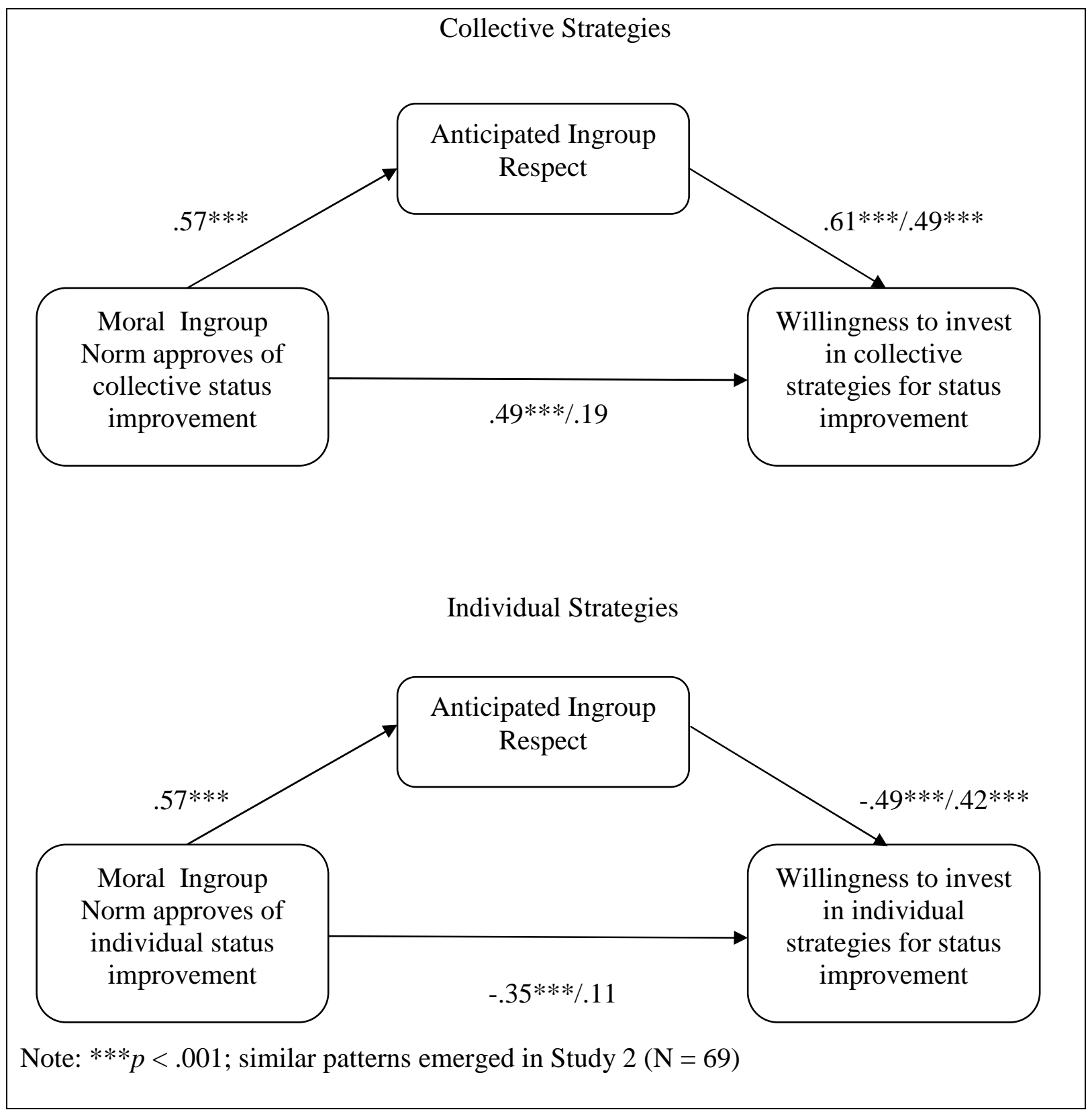

(Source: Pagliaro, S., Ellemers, N., \& Barreto, M. (2011). Sharing moral values: Anticipated in-group respect as a determinant of adherence to morality-based (but not competence-based) group norms. Personality and Social Psychology Bulletin, 37, 1117-1129. by <<SAGE Publications Ltd. $>>\mid<<$ SAGE Publications, Inc. $>>$, All rights reserved. (C 2011) 